\title{
Broadband frequency-dependent amplification of seismic waves across Bucharest, Romania
}

\section{Journal Article}

\section{Author(s):}

Sudhaus, Henriette; Ritter, Joachim

Publication date:

2009-10-01

\section{Permanent link:}

https://doi.org/10.3929/ethz-b-000086368

\section{Rights / license:}

In Copyright - Non-Commercial Use Permitted

\section{Originally published in:}

Journal of Seismology 13(4), https://doi.org/10.1007/s10950-008-9140-0 


\title{
Broadband frequency-dependent amplification of seismic waves across Bucharest, Romania
}

\author{
Henriette Sudhaus • Joachim Ritter
}

Received: 3 July 2007 / Accepted: 11 September 2008 / Published online: 17 October 2008

(C) Springer Science + Business Media B.V. 2008

\begin{abstract}
The determination of seismic amplitude amplification is a fundamental contribution to seismic hazard assessment. While often only highfrequency amplitude variations $(>1 \mathrm{~Hz})$ are taken into account, we analyse broadband waveforms from 0.14 to $8.6 \mathrm{~Hz}$ using a temporary network of 32 stations in and around the earthquake-prone city of Bucharest. Spectral amplitudes are calculated with an adaptive multiple-taper approach. Across our network (aperture $25 \mathrm{~km} \times 25 \mathrm{~km}$ ), we find a systematic northwest/southeast-oriented structural influence on teleseismic P-wave amplitudes from 0.14 to $0.86 \mathrm{~Hz}$ that can be explained by constructive interference in the dipping Cenozoic sedimentary layers. For higher frequencies $(1.4-8.75 \mathrm{~Hz})$, more local site effects prevail and can be correlated partly among neighbouring stations. The transition between systematic and localised amplitude variations occurs at about $1 \mathrm{~Hz}$.
\end{abstract}

H. Sudhaus $(\varangle)$

Institute of Geophysics, ETH Zurich, Sonneggstr.5, 8092 Zurich, Switzerland

e-mail: sudhaus@erdw.ethz.ch

J. Ritter

Geophysical Institute, Universität Karlsruhe (TH),

Hertzstr. 16, 76187 Karlsruhe, Germany
Keywords Site effects • Seismic amplification • Frequency-dependent amplification . Spectral ratios $\cdot$ Multiple taper $\cdot$ Bucharest • Vrancea

\section{Introduction}

The measurement of the local amplification characteristics of earthquake waves, so-called site effects, is important to estimate the damage during earthquake scenarios. As resonant frequencies of residential buildings a few stories high are typically above $1 \mathrm{~Hz}$ and short-period seismological sensors are mostly used, this part of the seismic wavefield is usually analysed for hazard assessment. However, in Bucharest, the capital of Romania, the fundamental frequency range of many vulnerable buildings is $0.5-1.5 \mathrm{~Hz}$ (Lungu et al. 1994); such low frequencies are also observed during earthquake shaking (Aldea et al. 2004; Moldoveanu et al. 2004). These buildings are multi-storied (from nine to eleven floors), and they have already been partly damaged by World War II actions and major earthquakes in 1940, 1977 and 1986 (Lungu et al. 1999a). The analysis of historic earthquake damage also indicates the importance of evaluating low-frequency site effect in Bucharest (Georgescu 2004). Our study provides additional details about seismic amplitude variations and site effects, particularly 
their frequency dependence, because we investigate broadband $(0.14-8.6 \mathrm{~Hz})$ seismological recordings. The dataset was gathered in the city of Bucharest and its outskirts (Fig. 1) where a deep sedimentary basin and laterally heterogeneous fluvial deposits significantly influence seismic amplitudes. Bucharest and its surroundings with 2.5 million inhabitants are threatened by strong earthquakes occurring in the Vrancea Region (Fig. 1), the most active part of the southeastern Carpathian orogenic belt (Atanasiu 1959; Radu 1974; Wenzel et al. 1999a, b; Musson 1999). The Vrancea seismicity is characterised by major earthquakes at intermediate focal depths of 80 $150 \mathrm{~km}$ and a hypocentral distance of only about $150 \mathrm{~km}$ from Bucharest. The maximum intensity of the Vrancea earthquakes reached VIII-IX in the city (Mândrescu and Radulian 1999) when the last disastrous earthquake of magnitude $M_{\mathrm{w}} \sim$ 7.5 in March 1977 caused major damage and killed more than 1,500 people. On average, there are about three to four earthquakes with magni- tudes $M_{\mathrm{w}}>7$ per century (Radu 1974; Wenzel et al. 1999b) that constantly threaten the whole metropolitan area (Sokolov et al. 2004). As Bucharest is built on the deep foreland basin of the Southern Carpathian arc (Fig. 1), the seismic wave amplitudes become amplified in the sedimentary layers (Cioflan et al. 2004; Mandrescu et al. 2007). The whole sedimentary rock sequence reaches a depth of about $8-10 \mathrm{~km}$ with up to several tens of meters of weakly consolidated fluvial sediments at the surface. The thickness of the sedimentary layers generally increases from south to north (e.g. Mândrescu et al. 2004). The near-surface layers vary later ally within the metropolitan area of Bucharest, and this complex three-dimensional structure results in considerable seismic site effects.

The sediments beneath Bucharest have been well investigated in the past in shallow geophysical studies (for a summary, see Mândrescu et al. 2004), major seismic experiments like the lithospheric-scale refraction profiles VRANCEA99 and
Fig. 1 Map of SE Romania with the Carpathian Arc. The epicentres of the nine studied Vrancea earthquakes are plotted with stars, the URS network in the metropolitan area of Bucharest is indicated by crosses. The inset shows SE Europe for the regional context

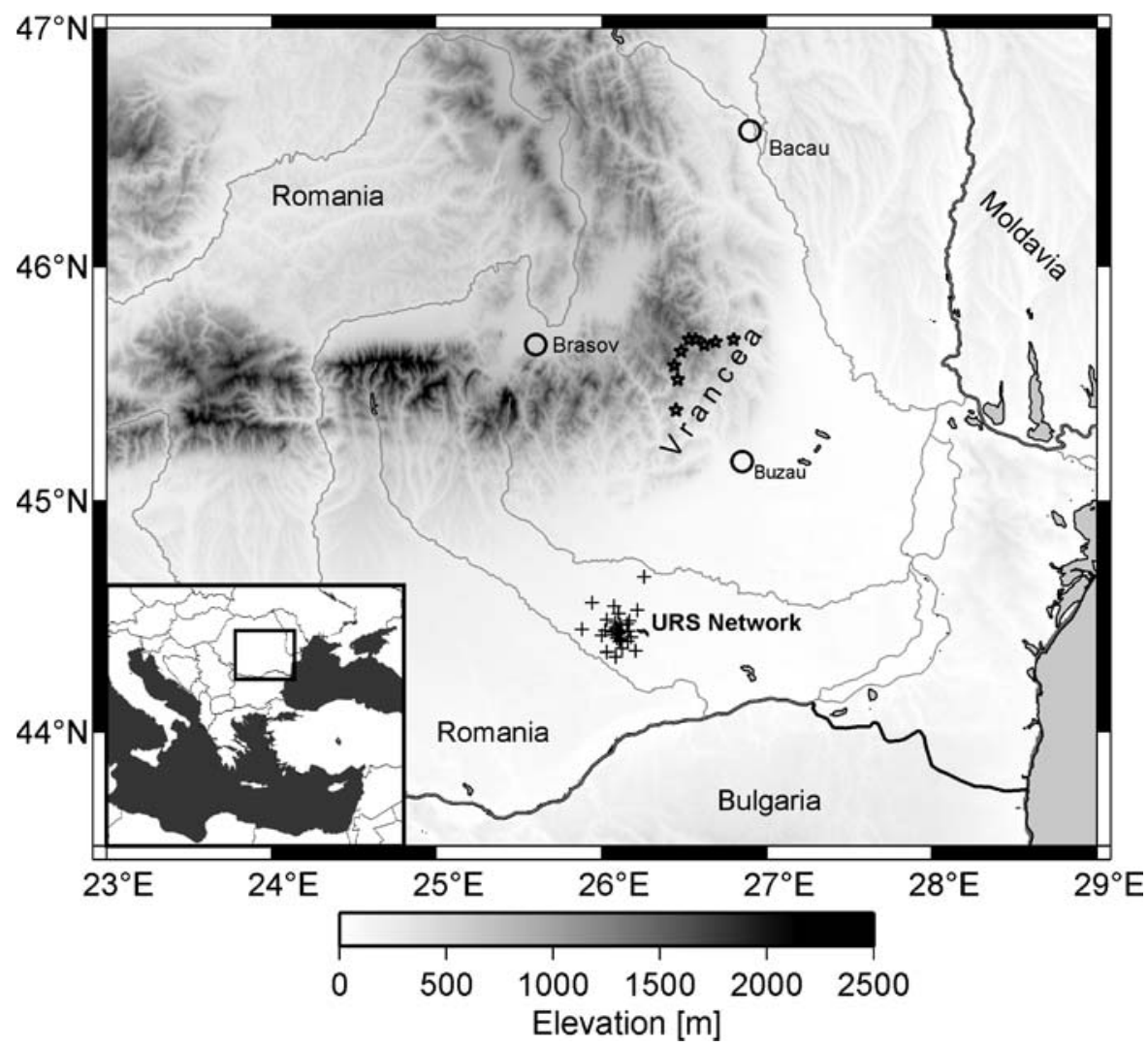


VRANCEA2001 (Hauser et al. 2001, 2002; Raileanu et al. 2005) and combined seismic-drilling projects (Lungu et al. 1999a, b; Mândrescu et al. 2004; Bala et al. 2005). Recent strong motion studies, conducted to determine the peak ground acceleration (PGA) for risk assessment, revealed a strong spatial and frequency-dependent variability of PGA across the city (e.g. Wirth et al. 2003; Aldea et al. 2004; Cioflan et al. 2004; Bartlakowski et al. 2006) as well as a dependence on the absolute seismic amplitude (Mândrescu et al. 2004).

Both the Collaborative Research Centre 461 "Strong Earthquakes" at the Universität Karlsruhe (TH) and the Romanian Group for Strong Vrancea Earthquakes have extensively investigated the tectonics, hazard and risk mitigation of the region (e.g. Wenzel et al. 1999a). Within the framework of this research, the Geophysical Institute at Karlsruhe and the National Institute for Earth Physics at Bucharest conducted a major seismological experiment called URS (URban Seismology) in the Bucharest metropolitan area (Fig. 2). The aim of URS was to measure local, regional and teleseismic events as well as the natural and cultural seismicity of the city and its surroundings to acquire a high-quality dataset for various seismological analysis techniques (Ritter et al. 2005). In this study, we investigate the frequency dependence of the seismic wave amplification in and around the city of Bucharest.
Fig. 2 Map of the Bucharest area and the broadband URS station network in 2003/2004.

The main Bucharest municipality is approximately inside the ring road. River and lakes are plotted in blue; houses, industry, etc. in grey; roads and streets in black. Numbers indicate URS stations names and different symbols indicate sensors used at the station sites. URS29, which is used as reference station for the spectral ratios, is shown in red

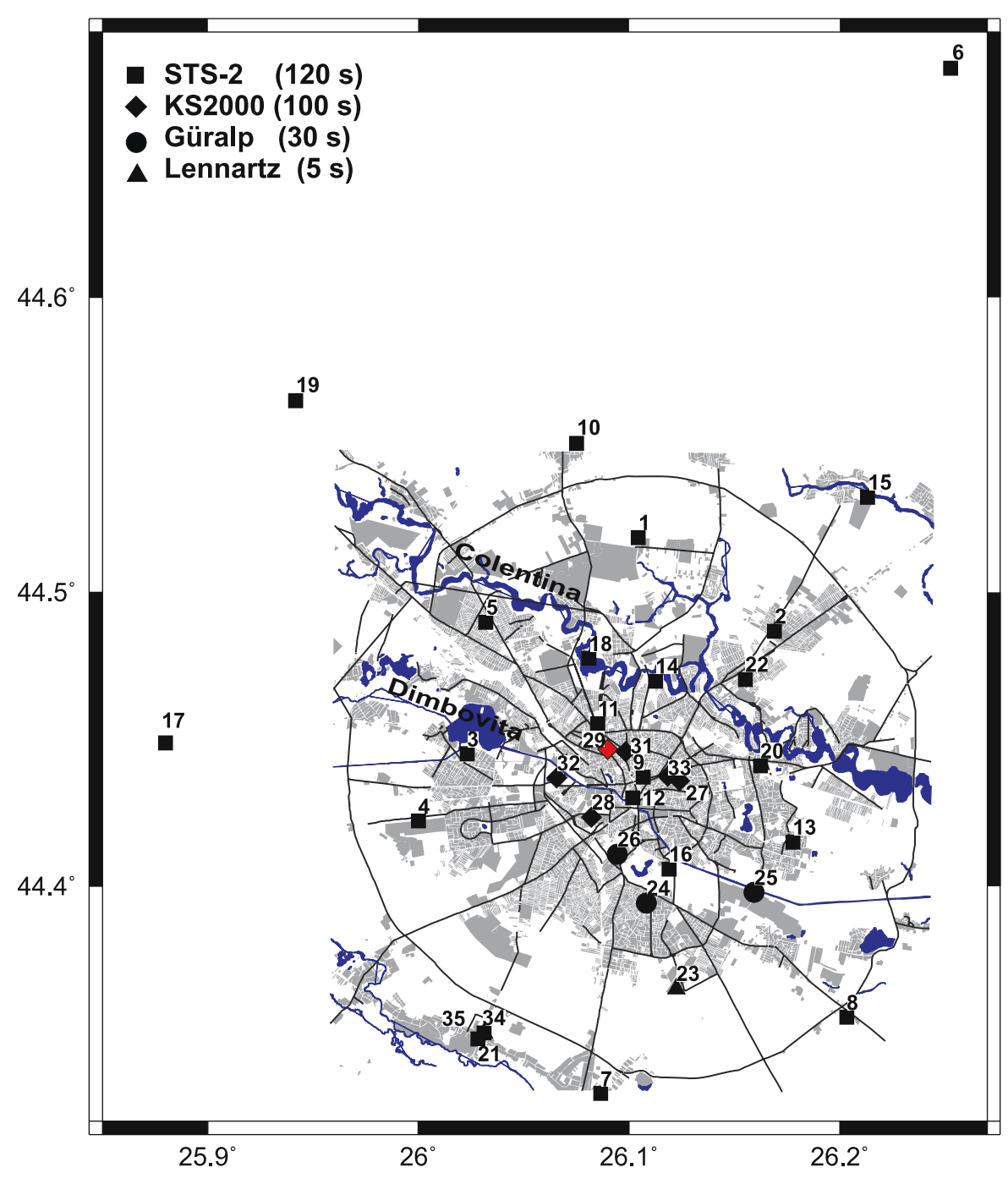


Table 1 Source parameters of the analysed teleseismic earthquakes

\begin{tabular}{|c|c|c|c|c|c|c|}
\hline Source region & Date & Origin time & Depth $(\mathrm{km})$ & $M_{\mathrm{W}}$ & $\Delta\left(^{\circ}\right)$ & $\mathrm{BAZ}\left({ }^{\circ}\right)$ \\
\hline Honshu, Japan & $10 / 31 / 2003$ & $01: 06: 28$ & 10 & 7.0 & 80.05 & 46 \\
\hline Kyrgyzstan & $12 / 01 / 2003$ & $01: 38: 32$ & 10 & 5.9 & 38.81 & 73 \\
\hline Indian Ocean & $01 / 11 / 2004$ & 04:32:48 & 5 & 6.2 & 84.45 & 158 \\
\hline Strait of Gibraltar & $02 / 24 / 2004$ & $02: 27: 46$ & 0 & 6.4 & 24.77 & 258 \\
\hline Xizang, China & $03 / 27 / 2004$ & $18: 47: 30$ & 8 & 6.0 & 48.93 & 80 \\
\hline Afghanistan/Tadzhikistan & $04 / 05 / 2004$ & $21: 24: 04$ & 187 & 6.5 & 34.72 & 87 \\
\hline Kamchatka & $04 / 14 / 2004$ & 01:54:09 & 51 & 6.1 & 71.12 & 24 \\
\hline Sicily & $05 / 05 / 2004$ & $13: 39: 43$ & 229 & 5.5 & 10.39 & 239 \\
\hline Kamchatka & 06/10/2004 & $15: 19: 57$ & 189 & 6.9 & 72.90 & 25 \\
\hline
\end{tabular}

$\Delta$ is the epicentral distance and BAZ the back azimuth to the source (epicentral data from National Earthquake Information Center, US Geological Survey)

We analyse short time windows spanning phase arrivals of teleseismic $(0.14-0.86 \mathrm{~Hz})$ and Vrancea $(0.5-8.75 \mathrm{~Hz})$ events, which we taper with the multiple-taper technique before transforming them into the spectral domain. We then determine the variation of spectral amplitudes for different frequencies across the network and interpret these results.

\section{The URS experiment and data selection}

The URS experiment (Fig. 2) was conducted in the metropolitan area of Bucharest to study the crustal seismic structure and site effects over a broad frequency range $(0.08-45 \mathrm{~Hz})$. The complete network was operating for 9 months from October 2003 until August 2004, and it continuously recorded the ground velocity with a sampling frequency of $100 \mathrm{~Hz}$ (for details on URS, see Ritter et al. 2005). We used 31 broadband stations at 34 network sites (Fig. 2) belonging to the portable KArlsruher BroadBand Array (KA BBA). As sensors, we deployed 22 Streckeisen
STS-2 (free period 120 s), five Geotech KS2000 (100 s), three Güralp (30 s) and one Lennartz (5 s) seismometers. The sensors were connected to Earthdata 24-bit data loggers, and a flat frequency response can be expected for frequencies above the free period. Prior to the installation of URS, we tested the accuracy of the instrument's amplitude response. The equipment was therefore installed in a storehouse, and the closely arranged sensors recorded seismic events for 4 weeks in summer 2003. Based on these measurements, we find relative amplification factors with an average error of less than 3\% for the particular instruments. Accordingly, we regard amplitude variations in the URS dataset as significant if variations exceed $5 \%$ between different station sites.

The data were filtered, and $\mathrm{P}$ - and S-wave phases with a signal-to-noise ratio $(\mathrm{S} / \mathrm{N})$ higher than 3 were selected from teleseismic and Vrancea events. Teleseismic P-phase arrivals were filtered with an acausal Butterworth bandpass filter of order 4 and corner frequencies at 0.05 and $3.0 \mathrm{~Hz}$. Nine suitable events with a clear P-wave were selected (Table 1). No teleseismic S-waves were
Table 2 Source parameters of analysed earthquakes in the Vrancea region

$\Delta$ is the epicentral distance relative to station URS9 (data from ROMPLUS catalogue, (Oncescu et al. 1999) and updates)

\begin{tabular}{llllllr}
\hline Date & Origin time & Latitude & Longitude & Depth $(\mathrm{km})$ & $M_{\mathrm{W}}$ & $\Delta(\mathrm{km})$ \\
\hline $11 / 25 / 2003$ & $23: 21: 39$ & 45.39 & 26.45 & 130 & 3.5 & 98 \\
$01 / 21 / 2004$ & $05: 49: 11$ & 45.52 & 26.46 & 117 & 4.1 & 120 \\
$02 / 07 / 2004$ & $11: 58: 22$ & 45.67 & 26.62 & 143 & 4.4 & 129 \\
$02 / 13 / 2004$ & $17: 48: 40$ & 45.68 & 26.69 & 129 & 3.8 & 131 \\
$03 / 17 / 2004$ & $23: 42: 08$ & 45.69 & 26.53 & 157 & 4.1 & 129 \\
$04 / 04 / 2004$ & $06: 41: 05$ & 45.64 & 26.48 & 150 & 4.3 & 123 \\
$07 / 02 / 2004$ & $01: 38: 08$ & 45.69 & 26.80 & 109 & 3.8 & 135 \\
$07 / 10 / 2004$ & $00: 34: 58$ & 45.69 & 26.57 & 150 & 4.3 & 129 \\
$07 / 22 / 2004$ & $17: 09: 30$ & 45.58 & 26.44 & 147 & 4.2 & 117
\end{tabular}


selected because their $\mathrm{S} / \mathrm{N}$ was below 3 at frequencies over $0.05 \mathrm{~Hz}$. The low $\mathrm{S} / \mathrm{N}$ is a result of the P-coda that reverberates in the sedimentary layers. The seismograms of Vrancea events were filtered with the same Butterworth bandpass but with corner frequencies of 0.3 and $10 \mathrm{~Hz}$. Nine of these events had clear P- and S-wave arrivals (Table 2 and Fig. 1) with $\mathrm{S} / \mathrm{N}>3$. For the S-wave analysis, E-W component recordings were used, as the northern source location (Fig. 1) means the E-W motion approximately corresponds to the horizontally polarised transverse S-wave. To avoid misinterpretation of observed amplitude variations, the seismograms of the Vrancea earthquakes were additionally corrected for geometrical spreading effects across the network.

In Fig. 3, waveform examples of a teleseismic P-phase as well as a P-phase and S-phases of a Vrancea event are displayed for a selection of stations. These waveforms are disturbed by varying noise conditions as expected in a metropolitan area. The teleseismic signals (Fig. 3a) are quite coherent, whereas the waveforms of the Vrancea event vary within the URS network, in particular those of the shear waves. Due to the sourcereceiver configuration with a back azimuth of about $10^{\circ}$, the E-W component motions correspond to transverse shear waves and N-S component motions correspond to radial shear waves. In the following, we only use the transversely polarised S-waves, which are more relevant for hazard studies than vertically polarised S-waves.

\subsection{Data processing}

The recorded waveforms were corrected for their individual instrument characteristics. To transform the seismic signal from the time into the spectral domain, we selected time window lengths and positions based on the required frequency content and duration of the analysed seismic phases. The time window should enclose the investigated seismic phase completely, but noise and coda waves should be avoided. As the length of the time window determines the spectral resolution, we chose a common length for each phase type so that the waveforms consistently fit into the time window in the recordings at all

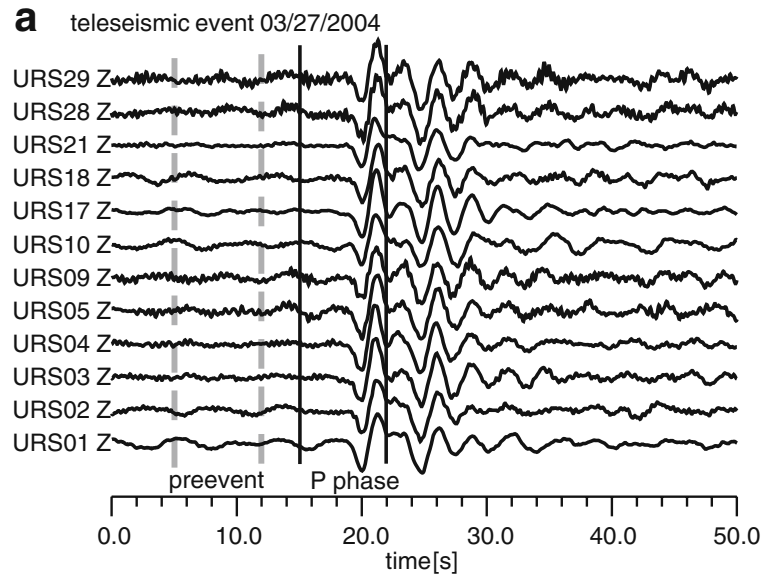

b local event 02/07/2004

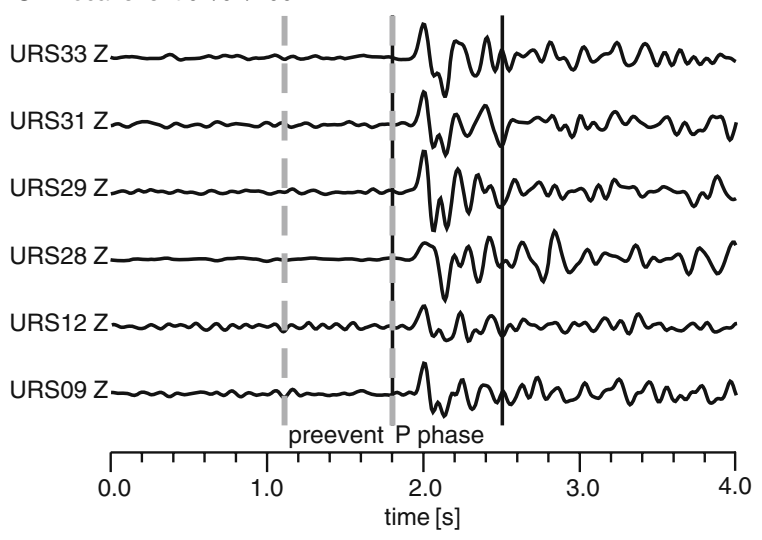

C local event 02/07/2004

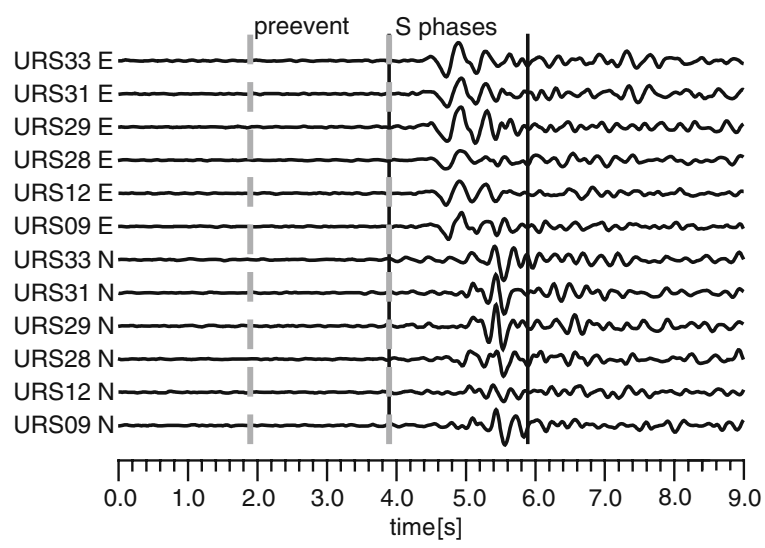

Fig. 3 Examples of analysed seismic waveforms at selected sites: a teleseismic P-phase (0.05-3.0 Hz-bandpass-filtered) of an event in China with $M_{\mathrm{w}}=6.0$ at $49^{\circ}$ distance; b P-phase $(0.3-10 \mathrm{~Hz})$ of a Vrancea event with $M_{\mathrm{w}}=3.8$, depth $=109 \mathrm{~km} ;$ c S-phase $(0.3-10 \mathrm{~Hz})$ of the Vrancea event (EW-component $\sim$ transverse motion; NScomponent $\sim$ radial motion). The vertical lines mark the time windows used for the spectral analysis; black solid lines for time window with seismic phase; grey dashed line for time window with pre-event noise 
URS stations. The time windows are $7 \mathrm{~s}$ long for the teleseismic P-phases. The Vrancea P-wave and transverse $\mathrm{S}$-wave phases were analysed with time window lengths of 0.7 and $2 \mathrm{~s}$, respectively. These three different lengths correspond to frequency resolutions of $0.14,1.4$ and $0.5 \mathrm{~Hz}$ (the spectral resolution is proportional to the inverse window length). The duration of the teleseismic P-phases from the different events varies to a certain extent. Accordingly, the time window length needs to be selected with respect to the duration of the longest phase. We set the position of the time windows so that their ends coincide with the visible end of the analysed phase (Fig. 3). Thus, we avoid sampling of different amounts of coda energy at different stations, which would affect the spectral amplitudes.

From Fig. 3, it is obvious that the noise level at the different sites varies considerably. To take into account these different recording conditions, we not only selected time windows of seismic phases but of pre-event noise as well. Assuming that the noise is stationary and stable over the time spanned by both time windows, we subtract the spectral noise energy from the seismic signal energy prior to the amplitude determination.

\subsection{Method}

The time-frequency transformation of short time windows (0.7-7 s) not only results in a coarse spectral resolution, but also the relative amount of spectral leakage (the smearing of energy from one discrete spectral value to the adjacent frequencies) is higher than for longer time windows. To suppress spectral leakage, we applied the adaptive multiple-taper approach (Park et al. 1987; Percival and Walden 1993). Each time series was separately tapered with the first four loworder $3 \pi$ discrete prolate spheriodal sequences (dpss, Fig. 4) after Slepian (1978) or Percival and Walden (1993). Afterwards, squared Fourier amplitude spectra $S_{k}(f)$ (modified or windowed periodograms, Slepian 1978) were calculated:

$S_{k}(f)=\Delta t\left|\sum_{t=1}^{N} v_{t} h_{k, t} e^{-i 2 \pi \cdot f t \Delta t}\right|^{2}$,

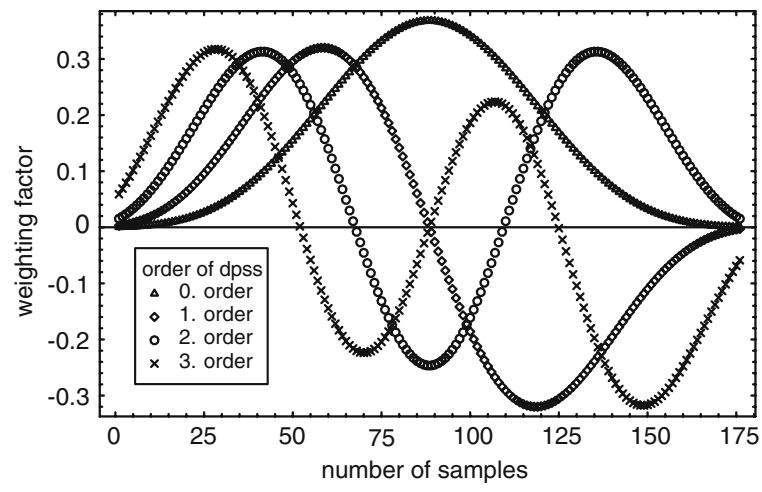

Fig. 4 Taper functions used: Four lowest order $3 \pi$ discrete prolate spheriodal sequences (dpss) for 176 samples

with $v_{t}$ being the $N$ samples of the seismogram within the time window and $\Delta t$ the sampling interval. $h_{k, t}$ is the $k$ th taper function modifying the time window. The modified periodograms $S_{k}(f)$, or power spectra, is discrete because of the time window's finite length. It is defined for multiples of the minimum resolvable frequency $f_{\min }$ :

$f_{\text {min }}=1 / N \cdot \Delta t$.

The multiples of $f_{\min }$ are the discrete frequencies used below. We determine the multiple taper spectrum $S_{\mathrm{m}}(f)$ from the weighted sum (adaptive multiple taper) of the resulting power spectra $S_{k}(f)$. The applied weight function is frequencydependent and determined iteratively with the intention of optimally balancing the spectral leakage against resolution at each discrete frequency. The spectra tapered with lower order dpss therefore have higher weights at frequencies where the spectral amplitudes change rapidly. To do this, first, the weight factors for each taper function at each frequency are determined from a single window spectrum as a first-order approximation of the spectral shape. The weighted single-window spectra are then summed, and the shape of the obtained multiple-taper spectrum is again determined for refinement of the weight function (for details, see Percival and Walden 1993).

Although providing less resolution than singlewindow taper functions, multiple-taper spectra allow us to reliably estimate the spectral shape across the entire bandwidth (Percival and Walden 1993). Moreover, our study strongly benefits from 
the smoothness of these multiple-taper spectra, as summation of the single-window spectra enables the calculation of smooth and stable spectral ratios.

Examples of the discrete power spectra from seismic signals and pre-event noise in the analysed phases are shown in Fig. 5. For teleseismic phases, we find that the main signal energy lies in the lowfrequency range below $1 \mathrm{~Hz}$ (Fig. 5a). The phases from the Vrancea events have a bandwidth in the high-frequency range at $1-8 \mathrm{~Hz}$ for $\mathrm{P}$-waves and 1-6 Hz for S-waves. The S-waves are superposed on the P-wave coda, and at frequencies above $6 \mathrm{~Hz}$, the energy of the S-waves is lower than the energy of the P-wave coda. We therefore use only frequencies up to $6 \mathrm{~Hz}$.

The absolute value of the spectral amplitudes depends on the earthquake magnitude, the radiation pattern, the epicentral distance to the source, the source-side seismic structure and the receiverside site conditions. In the following, we consider normalised amplitude variations only and therefore neglect the event magnitudes which are similar for the studied Vrancea events (Table 2). As the distance between the sources and the URS network $(\sim 150 \mathrm{~km})$ is much larger than the URS network aperture $(40 \mathrm{~km})$, we can neglect the radiation pattern of the sources and the sourceside seismic structure. We only correct for the geometrical spreading of the Vrancea waveforms and assume that the remaining relative amplitude variations are caused mainly by site effects.

Since we are interested in the average relative amplitude variations of different seismic events across the network, we take the square root of the power-spectral amplitudes and apply a normalisation. For the teleseismic phases, we scale the amplitudes separately for each event with the maximum spectral amplitude at the URS network and calculate the median values for the discrete frequencies at each station. In Fig. 6a, the relative $\mathrm{P}$-wave amplitudes and their median values at $0.28 \mathrm{~Hz}$ are displayed for each station along with the nine teleseismic events (Table 1). The largest amplitudes were recorded at stations with amplification values close to 1 . For the phases of the Vrancea events, we calculated relative amplitudes with respect to reference station URS29 (indicated with red in Fig. 2). URS29 was selected as reference station because it recorded all investigated events and was located in the centre of the network (Fig. 2). A normalisation with respect to the maximum spectral amplitude as applied for the teleseismic waves is not suitable here due to the high amplitude variability above $1 \mathrm{~Hz}$ and

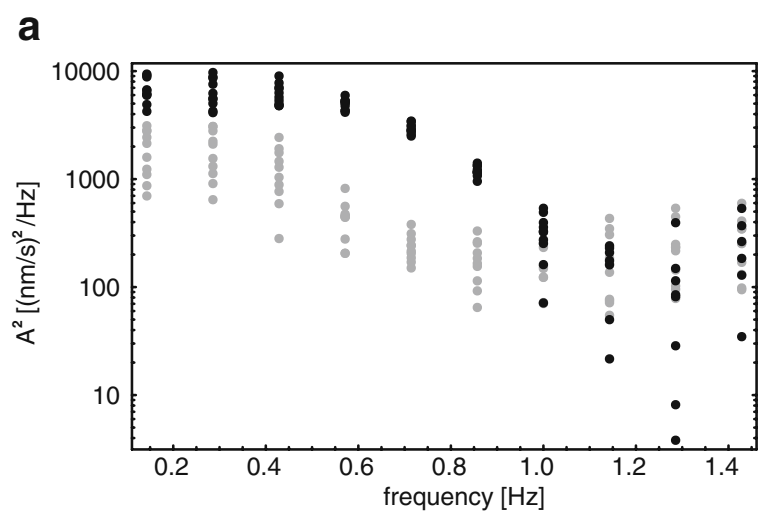

b
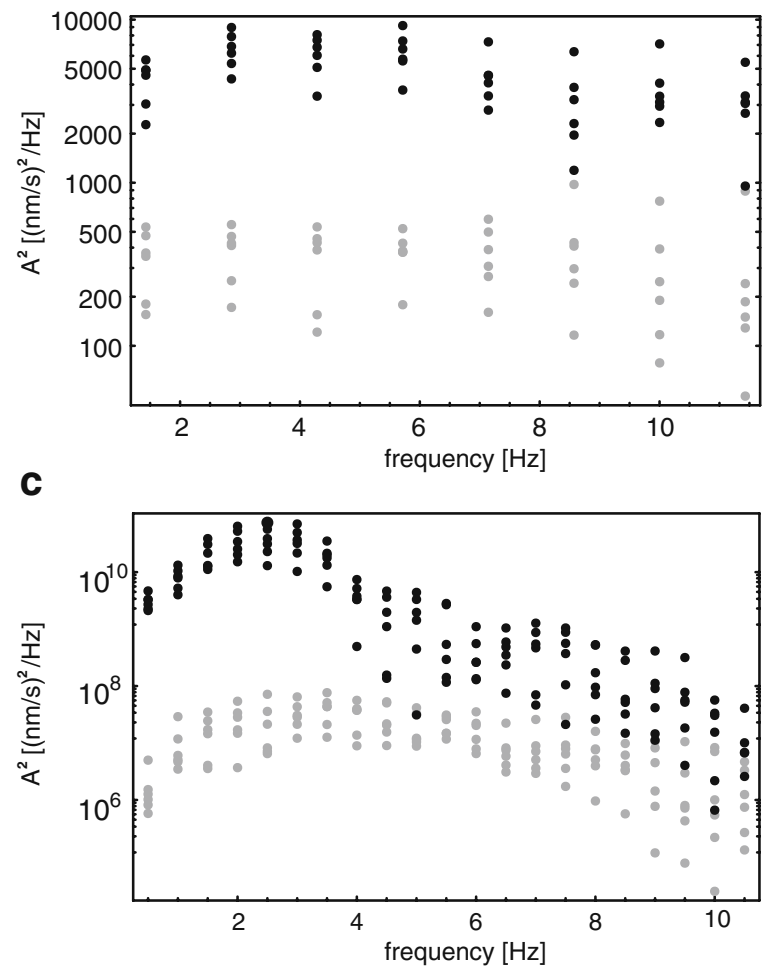

Fig. 5 Examples of power spectra for the recordings shown in Fig. 3. Black dots mark the discrete spectral values of the seismic phases, grey dots show the pre-event noise (see Fig. 3). a Teleseismic P-wave phase, b Vrancea P-wave phase and c Vrancea transverse S-wave 
Fig. 6 Relative spectral amplitudes (small symbols) and corresponding medians (grey squares) at each URS station for the events given in Tables 1 and 2. a Normalised spectral P-wave amplitudes for each teleseismic event at $0.28 \mathrm{~Hz}$, b spectral ratios relative to URS29 for Vrancea P-phases at $1.4 \mathrm{~Hz}$ and $\mathbf{c}$ spectral ratios for Vrancea transverse S-phases at $0.5 \mathrm{~Hz}$ a

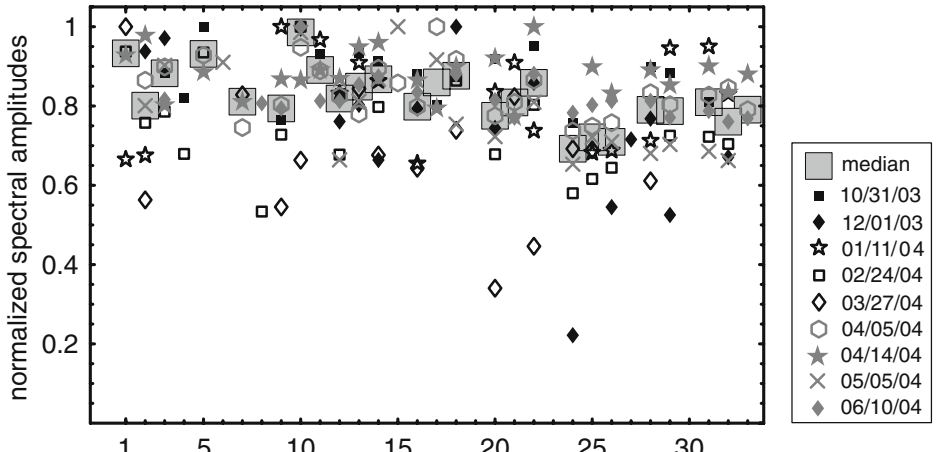

b

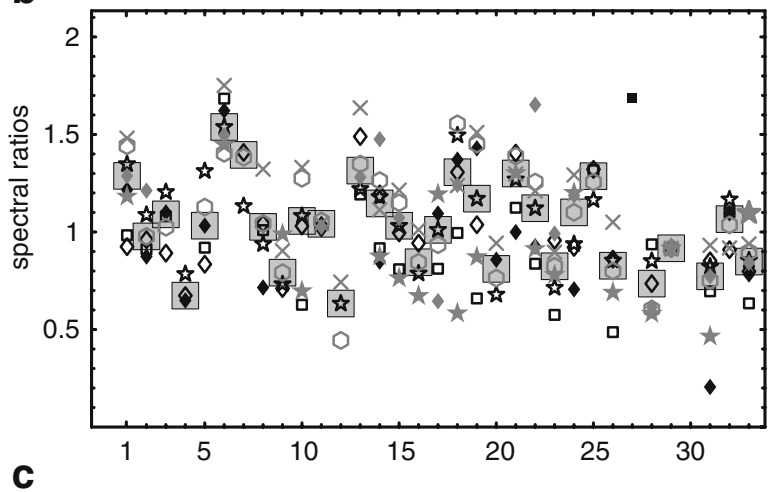

$\square$ median $\frac{M_{W}}{3.5}$

$\begin{array}{ll}\text { - } 11 / 25 / 03 & 3.5 \\ -01 / 21 / 04 & 4.1\end{array}$

\ 02/07/04 4.4

ㅁ 02/13/04 3.8

$\diamond 03 / 17 / 04 \quad 4.1$

- 04/04/04 4.3

$+07 / 02 / 043.8$

$\times 07 / 10 / 04 \quad 4.3$

- $07 / 22 / 04 \quad 4.2$

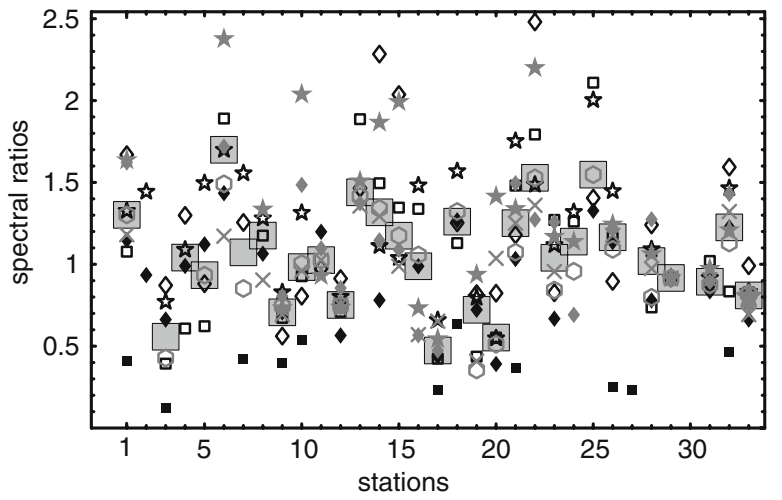

$\square$ median $\frac{M_{W}}{3.5}$

- 01/21/04 4.1

ث $02 / 07 / 04 \quad 4.4$

口 02/13/04 3.8

$\diamond 03 / 17 / 04 \quad 4.1$

$04 / 04 / 04 \quad 4.3$

$+07 / 02 / 043.8$

$\times 07 / 10 / 044.3$

$\begin{array}{r}07 / 22 / 04 \quad 4.2 \\ \hline\end{array}$ missing records which cause severe uncertainties. In Fig. 6b, c, the relative spectral amplitudes are presented at 1.43 and $0.5 \mathrm{~Hz}$ for the Vrancea Pwaves and transverse $\mathrm{S}$-wave phases, respectively. With increasing frequency, an increase of relative amplitude variations is visible for the single measurements as well as for the median values at the stations. Although the methods for determining median values for the teleseismic and Vrancea events differ, this has no significant effect on the relative amplitude variations, whereas absolute values cannot be calculated in this way. The standard deviations of the mean values are indicated on the maps by scaling of the symbols.

\section{Results}

We studied the relative amplitude variations for the complete frequency range $(0.14-0.86 \mathrm{~Hz})$ with clear seismic phase observations. Specifically, the results for the discrete frequency values resulting 
from the Fourier analysis are presented to avoid interpolation between these values. The lowfrequency end $(0.14 \mathrm{~Hz})$ is important because it may correspond to low-frequency shear waves or surface waves of Vrancea events. As our dataset does not contain clear low-frequency phases from Vrancea events due to their low magnitude during the URS experiment (Table 2), we use the teleseismic P-wave observations instead. The highfrequency range $(1.6-8.6 \mathrm{~Hz})$ is important for Bucharest because it corresponds to the resonance frequency of the buildings with by far most apartments (Lungu et al. 1999c).

The spectral amplitudes of the low-frequency teleseismic arrivals $(<1 \mathrm{~Hz})$ vary moderately. In Fig. 6a, the relative variation across the network at $0.28 \mathrm{~Hz}$ is shown as an example. Most variations in amplitude are within a $40 \%$ range. The individual amplitude values at several stations (e.g. URS02, 09, 20, 22 and 24) are scattered for some events. A more stable result is found using the median values for each station. The medians vary by about $30 \%$ for a frequency of $0.28 \mathrm{~Hz}$ (Fig. 6a); these values are above our measurement uncertainty of maximum 5\% (see above). To map the spatial amplitude variations, we plot the median amplitudes for the different frequencies at the recording locations (Fig. 7). These spatial representations show a clear pattern of frequency-dependent amplitude variations across the URS network: We observe a NW-SE trend of amplification change for frequencies from $0.14 \mathrm{~Hz}$ (Fig. 7a) to $0.71 \mathrm{~Hz}$ (Fig. 7e). At $0.14-0.43 \mathrm{~Hz}$, the relative amplitudes are higher by about $20 \%$ in the NW part of the network than in the central and southern parts. This pattern changes to a less coherent distribution at $0.57 \mathrm{~Hz}$ with increased amplitudes around the city centre. At $0.71 \mathrm{~Hz}$, a reverse trend is found in which higher amplitudes ( $30 \%)$ are measured in the south (Fig. 7e). At $0.86 \mathrm{~Hz}$ (Fig. 7f), we find relatively low amplitudes in the centre of the URS network that coincides with the Bucharest city centre. Higher relative amplitude values are observed at the surrounding sites. However, there is a larger standard deviation, as we are close to the noise level.

The relative amplitude variations of the Vrancea P-wave arrivals are shown in Fig. $6 \mathrm{~b}$ as spectral ratios relative to URS29. These values commonly show approximately $60 \%$ scatter. The median values are less well constrained than for the teleseismic data. For example, at URS31, the nearest station to URS29 in the city centre, we find much lower amplitude values for two events. However, most median values at the URS stations are quite stable, and between different stations, variations of the medians span 0.5 to 1.5 . In Fig. 8b-f, the medians at 1.43 to $8.75 \mathrm{~Hz}$ of the Vrancea P-waves are plotted in map view. The median spectral ratios of the teleseismic P-wave data at $0.86 \mathrm{~Hz}$ are added in Fig. 8a to enable a comparison with lower frequencies. The relative amplitude variation pattern in Fig. 8a (spectral ratio method) and Fig. 7f (normalisation per event) match well and demonstrate that the results of the two methods can be compared as long as we consider relative amplitudes.

The high-frequency $(>1 \mathrm{~Hz}) \mathrm{P}$-wave amplitude variations are locally stable and do not change systematically within the network across the studied frequencies (Fig. 8). Northwestern stations are characterised by higher amplitudes, while those in the southeast decrease in relative amplitude. However, there is no frequency dependence as for the teleseismic data, and instead, more spatially clustered anomalies are visible. For example, in the centre and towards the south, amplitudes are generally lower than in the north and periphery of Bucharest (Fig. 8b-f).

To gain insight into the frequency-dependent properties, the spectral ratios are plotted against frequency at the URS stations (Fig. 9). The area below the median spectral value is shaded, and, where possible, neighbouring stations are placed together. We find several similarities in the median spectral shape for groups of neighbouring stations: The northern and northwestern stations (URS1, 05, 06, 10, 14, 18 and 19) have higher median spectral ratios at lower frequencies $(<4 \mathrm{~Hz})$ than stations in the central part. More even spectral ratios are found in the centre of the network (URS9, 11, 12, 26, 28, 31, 32 and 33) and generally have lower amplitudes and less scattering of the median values than those observed at the nearby station URS29. At several stations (URS21, 13, 14, 22 and others), pronounced variations of the spectral ratios occur at least in some parts of the spectrum. This is believed to indicate the influence 
Fig. 7 Maps with median spectral P-wave amplitudes from the teleseismic waveforms at the URS network. The point size decreases with increasing standard deviation. a dominant frequency at $0.14 \mathrm{~Hz}$, b $0.28 \mathrm{~Hz}, \mathbf{c} 0.43 \mathrm{~Hz}$, d $0.57 \mathrm{~Hz}, \mathbf{e} 0.71 \mathrm{~Hz}$ and f $0.86 \mathrm{~Hz}$ a

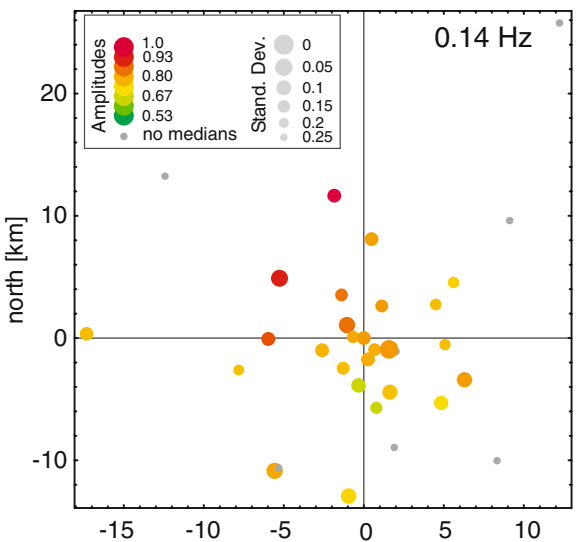

C

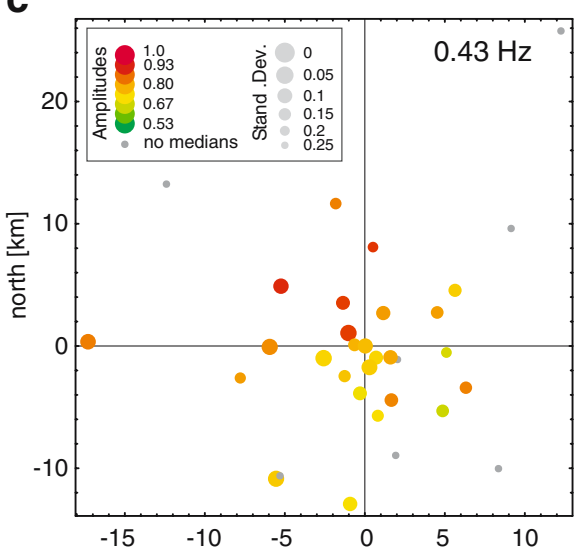

e

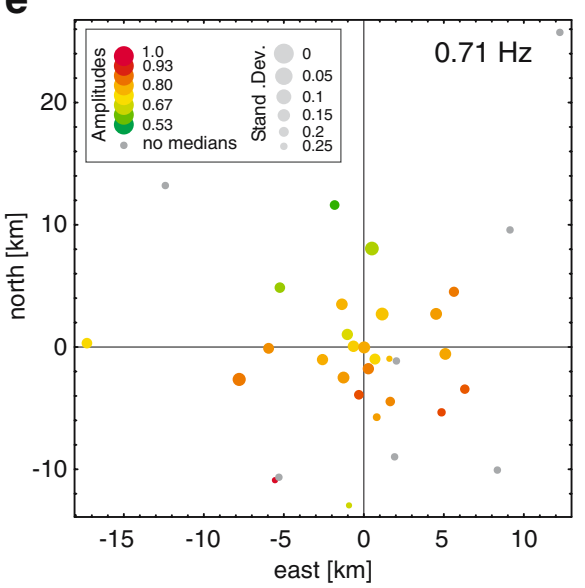

b

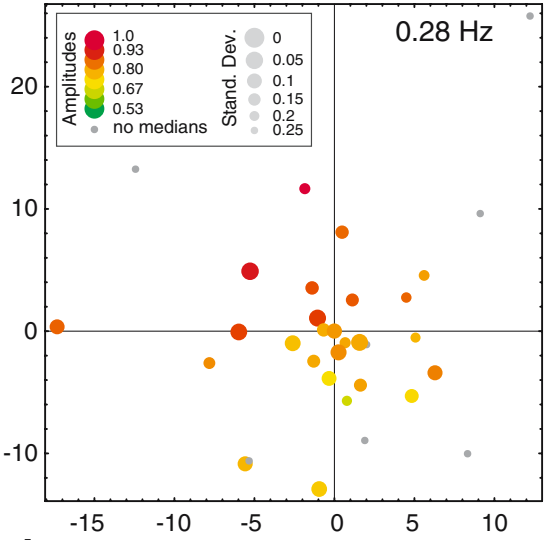

d

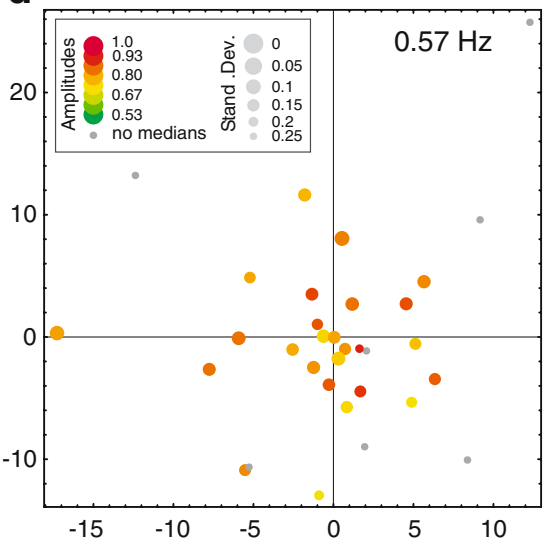

f

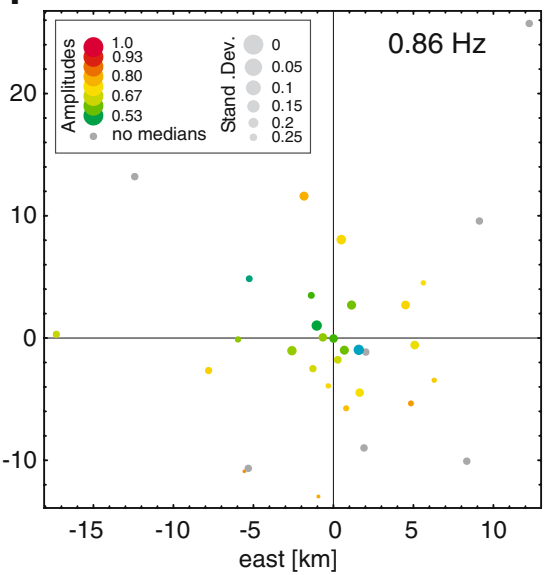

of very local site conditions on the seismic wave amplification.

The variation of transverse S-wave amplitudes from the Vrancea events across the network at $0.5 \mathrm{~Hz}$ is shown in Fig. 6c. It is stronger than for $\mathrm{P}$-waves (Fig. 6a, b) and reaches relative values of
0.1 to 2.5 . Most single relative S-wave amplitude variations span a range of about $80 \%$, and their median values vary by about $60 \%$ (Fig. 6c). The spatial distribution of the median S-wave amplitudes is shown in Fig. 10. At 0.5 and $1.0 \mathrm{~Hz}$, the lowest amplitudes are observed in the centre of 
Fig. 8 Maps with median spectral $\mathrm{P}$-wave amplitudes from the Vrancea waveforms at the URS network. The point size decreases with increasing standard deviation. a dominant frequency at $0.86 \mathrm{~Hz}$ for teleseismic events, b $1.43 \mathrm{~Hz}$ Vrancea events, c $2.86 \mathrm{~Hz}, \mathbf{d} 5.71 \mathrm{~Hz}$, e $7.14 \mathrm{~Hz}$ and $\mathbf{f} 8.75 \mathrm{~Hz}$ a

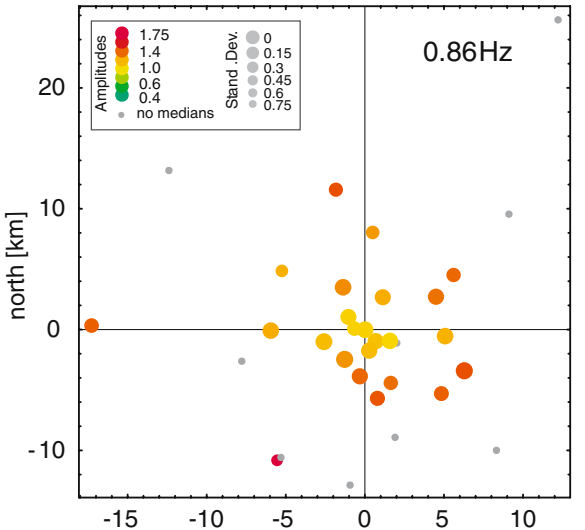

C

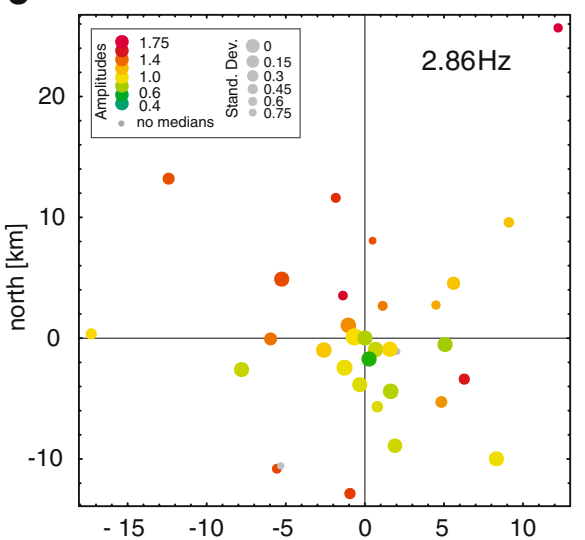

e

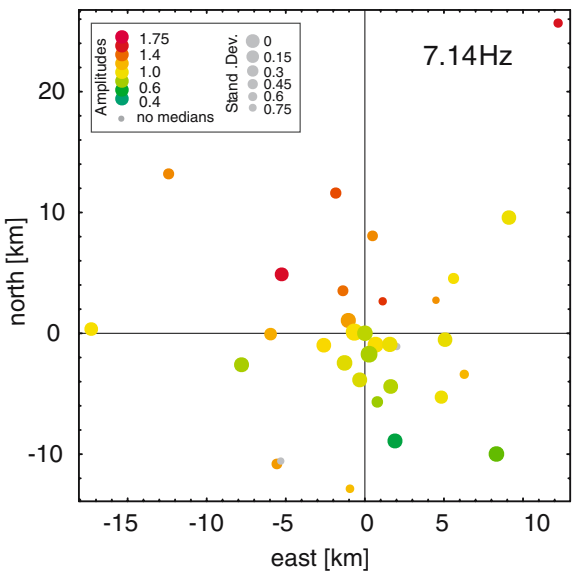

b

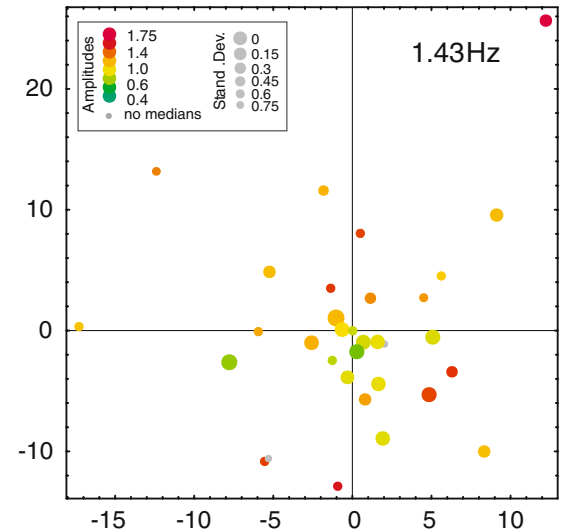

d

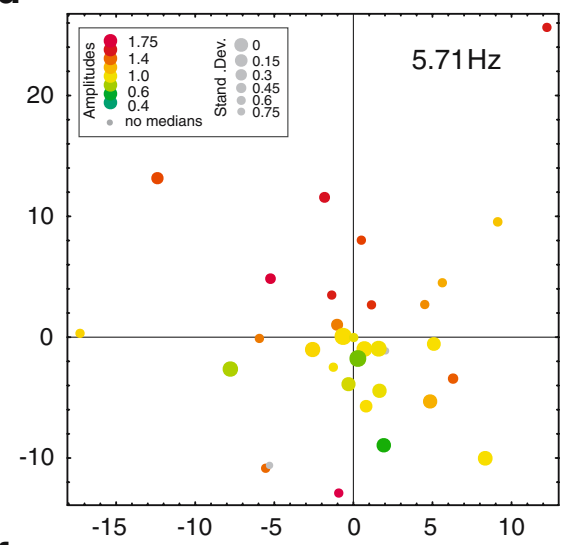

f

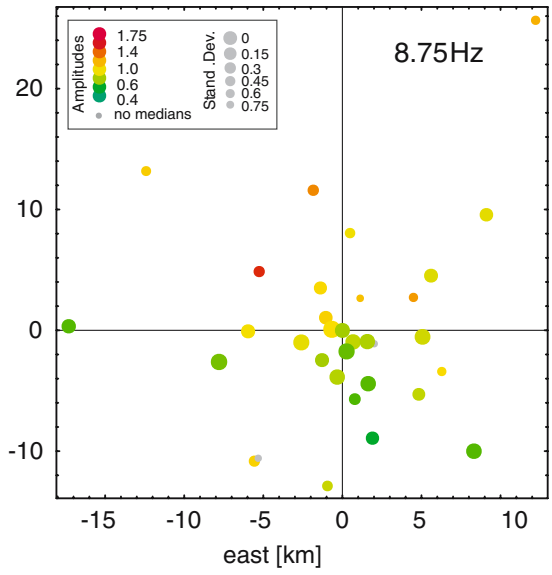

the city. At higher frequencies $(2-6 \mathrm{~Hz})$, the amplitudes are slightly increased in the city relative to its surroundings. The strongest amplitudes are found at station URS32 in the west of the city centre (Fig. 2). The spatial pattern of amplification in Fig. 10 is less frequency-dependent than the low-frequency teleseismic P-waves (Fig. 7) and shows more variability at short distances. Such variability points to small-scale local effects, as expected for typical seismic site effects. The variability of the S-wave amplitudes is also observed in the frequency-dependent spectral ratios 

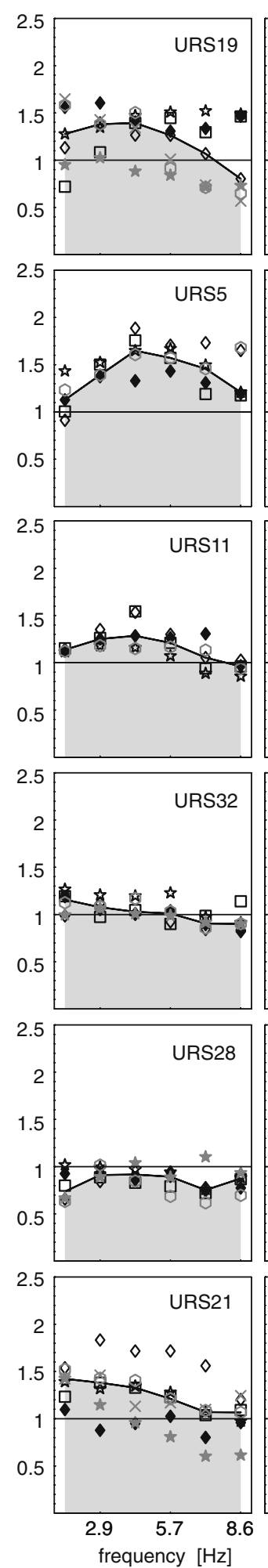
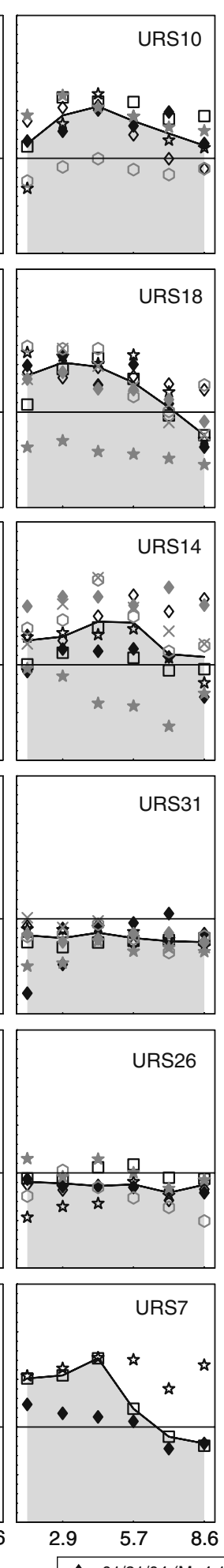

- 01/21/04 (M=4.1)

^ $02 / 07 / 04(\mathrm{M}=4.4)$
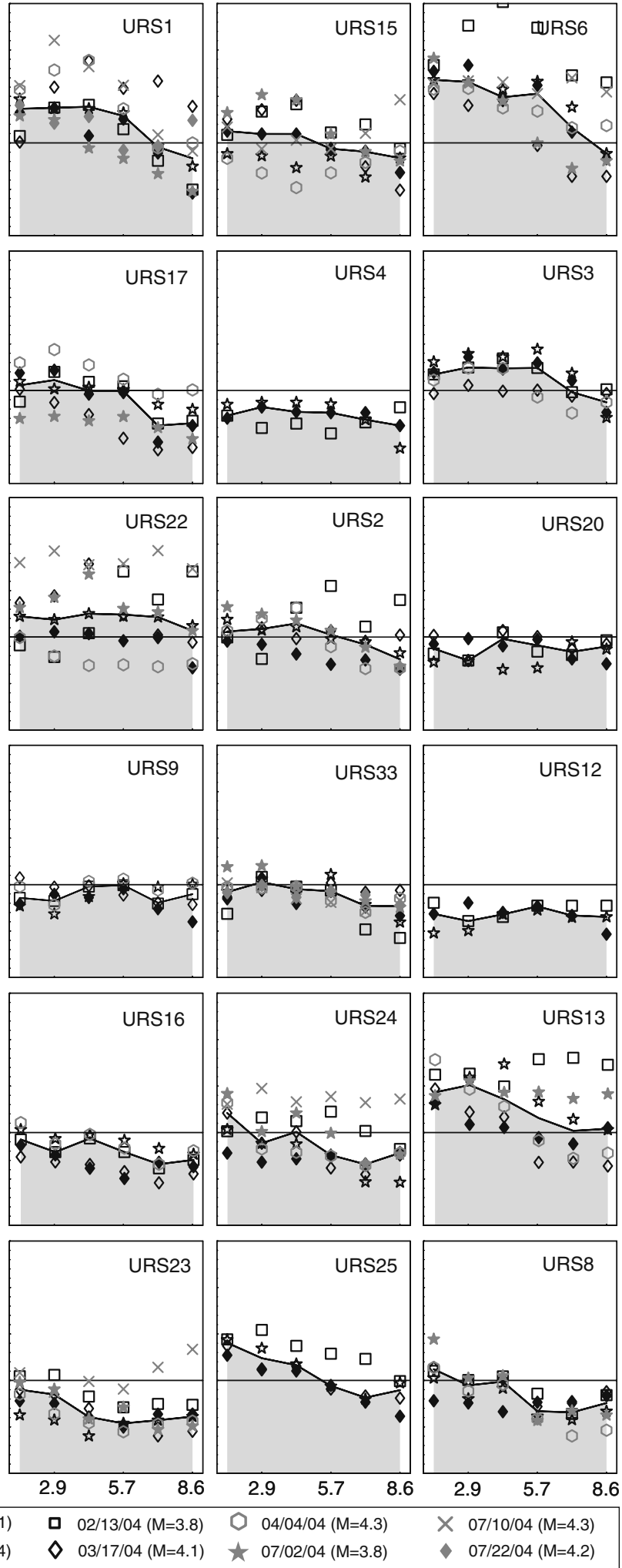
Fig. 9 Spectral amplitude ratios for the URS stations relative to station URS29 for P-waves of Vrancea events. The symbols indicate the values for different events; the area below the median is shaded in grey at different sites (Fig. 11). Strong scattering of the observed values is found at stations URS32, URS18, URS06 and URS21. The neighbouring stations URS31, URS9, URS33 and URS12 show
Fig. 10 Maps with median spectral S-wave amplitudes from the Vrancea waveforms (transverse component) at the URS network. Point size decreases with increasing standard deviation. a $0.5 \mathrm{~Hz}$, b $1.0 \mathrm{~Hz}, \mathbf{c} 2.0 \mathrm{~Hz}$, d $3.0 \mathrm{~Hz}$, e $4.0 \mathrm{~Hz}$ and f $6.0 \mathrm{~Hz}$
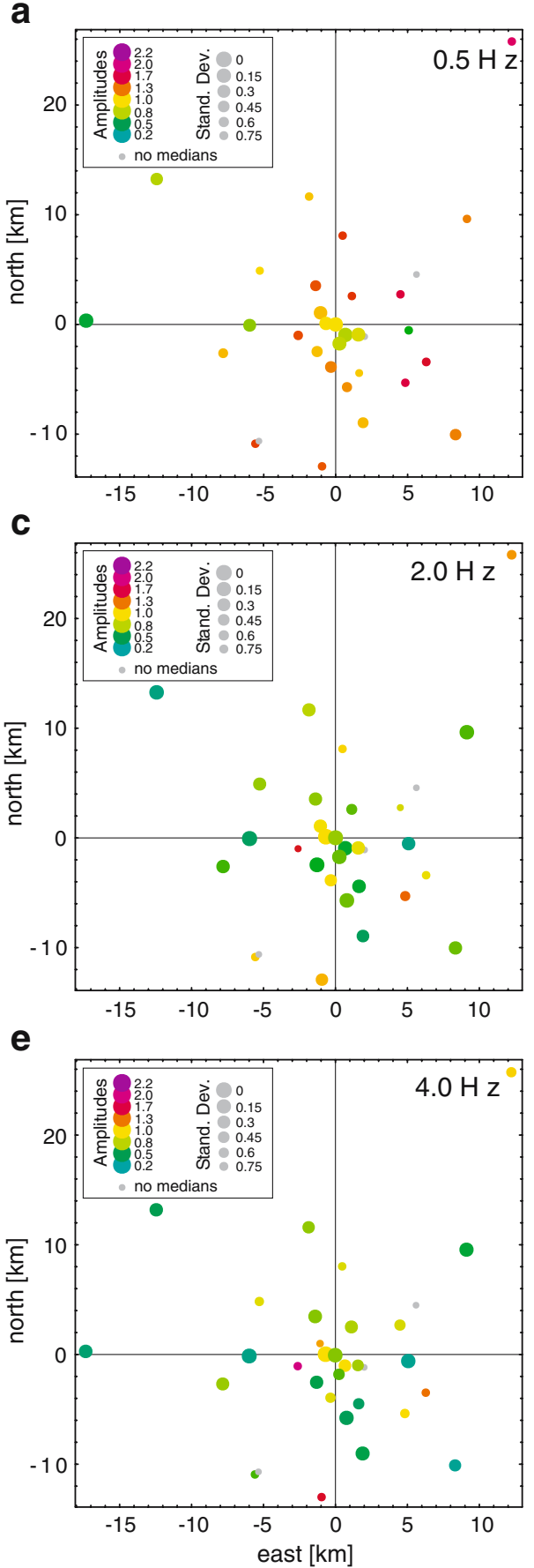

b

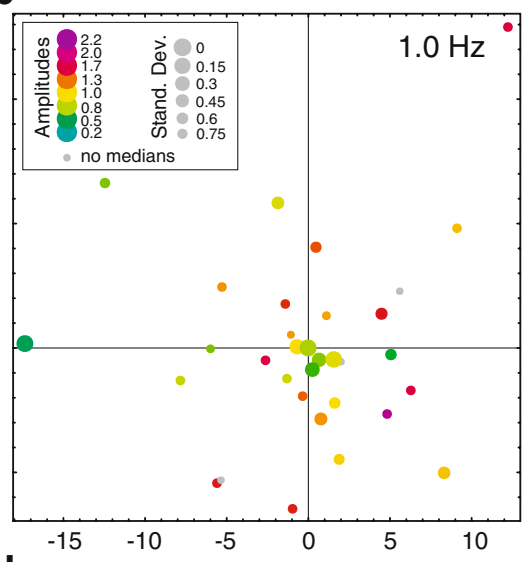

d

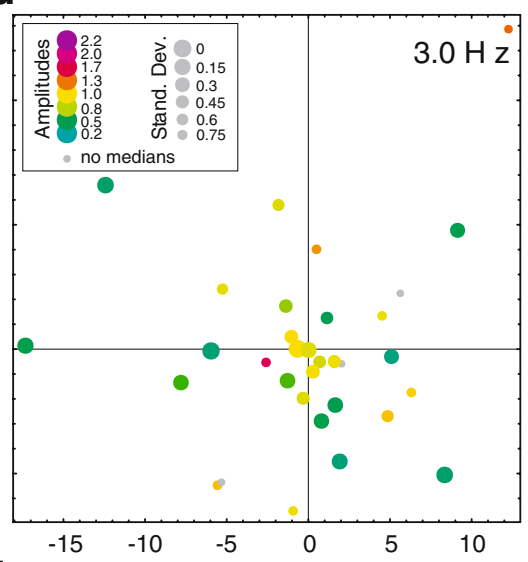

f

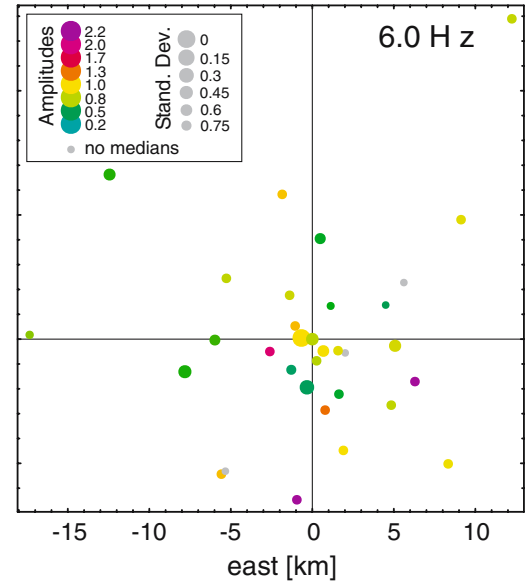



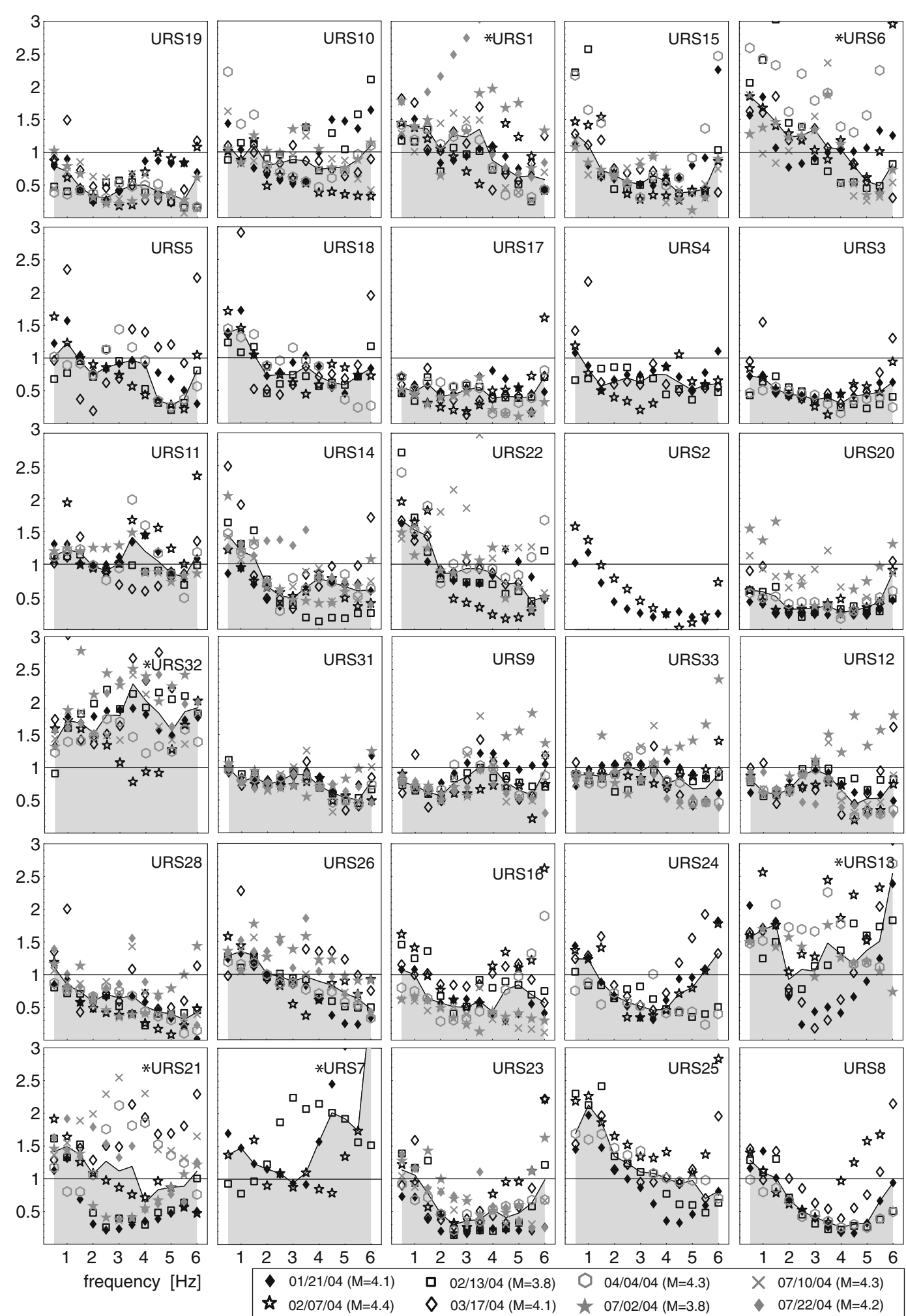

$\begin{array}{cccccccccccc}1 & 2 & 3 & 4 & 5 & 6 & 1 & 2 & 3 & 4 & 5 & 6 \\ 0 & 04 / 04 / 04 & (\mathrm{M}=4.3) & & \times & 07 / 10 / 04 & (\mathrm{M}=4.3) \\ \star & 07 / 02 / 04 & (\mathrm{M}=3.8) & & & 07 / 22 / 04 & (\mathrm{M}=4.2)\end{array}$


Fig. 11 Spectral amplitude ratios for the URS stations relative to station URS29 for transverse S-waves of Vrancea events. The symbols indicate the values for different events; the area below the median is shaded in grey. Stars at the station name mark stations where some spectral ratios exceed 3 and the range of the plots

the same frequency dependence as URS29 (Fig. 11), while most stations have increased S-wave amplitudes relative to URS29 at 1-2 Hz. Towards the east and south, high frequencies (4-6 Hz) are also relatively enhanced, which leads to bowlshaped spectral ratios. When comparing the distribution of the spectral ratios between $\mathrm{P}$ - and S-waves of Vrancea events (Figs. 9 and 11), we find similar frequency dependencies at stations with small amplification factors. Stations characterised by stronger amplification for P-waves generally also show stronger site effects for S-waves, though there are also few exceptions (e.g. URS19 and URS32), where the frequency-dependent $\mathrm{P}$-wave amplification pattern is reversed to the S-wave pattern.

\section{Discussion and interpretation}

Amplitude variations across a seismic network may be related to several factors, including wavefront focusing, scattering, superposition and nearsurface site effects. The spatial coherence of amplitude pattern is an important clue to the interpretation of the observations. Small-scale or sub-wavelength lateral structural heterogeneity mainly causes scattering of teleseismic wave fronts. This leads to randomly distributed and mostly weak amplitude changes that are often interpreted with random media approaches (e.g. Flatté and Wu 1988; Hock et al. 2004). Largescale structures spanning several wavelengths may cause laterally systematic amplitude variations. An example is the amplitude pattern at the Gräfenberg Array, Germany, which is due to a dipping sedimentary wedge (Weber 1994).

Our observed low-frequency $(<1 \mathrm{~Hz})$ NW-SE changing P-wave amplitude pattern (Fig. 7) across the area of Bucharest is likely to be caused by a systematic change of the geological structure at depth. A plausible physical mechanism is wave interference within a dipping layer to explain this pattern. Such a dipping reflector beneath Bucharest is indicated in the seismic refraction model VRANCEA99 (Hauser et al. 2001). The Cenozoic-Cretaceous boundary (CCB) is modelled by Hauser et al. (2001) as a P-wave velocity $\left(v_{\mathrm{p}}\right)$ jump from about $2.1-2.7 \mathrm{~km} / \mathrm{s}$ (partly consolidated Cenozoic sediments) to $5.3-5.8 \mathrm{~km} / \mathrm{s}$ (consolidated Mesozoic sediments) at a depth of about $2 \mathrm{~km}$. More precise information on this interface was collected by Mândrescu et al. (2004) from deep drillings conducted in the Bucharest area. Their interpolated map contains a clearly NNW dipping CCB. In the south of the URS network, the depth to the CCB is about $700 \mathrm{~m}$, and it increases with a depth gradient of $4 \%$ to about $2 \mathrm{~km}$ in the north (Mândrescu et al. 2004). Using high-resolution receiver functions, Diehl and Ritter (manuscript in preparation) find a dipping first-order seismic discontinuity below the URS network at $\sim 0.7-\mathrm{km}$ depth in the south and $\sim 1.5-\mathrm{km}$ depth in the north. This observation illustrates the relevance of this interface.

Frequency-dependent constructive interference in a dipping layer with a reflecting bottom varies with the thickness, $h$, of the layer. In the following, we assume a near-vertical incidence of the teleseismic waves into the seismic lowvelocity sediments below the URS network. The corresponding fundamental frequency $f_{0}$ for constructive interference is given by:

$f_{0}=\left\langle v_{p}\right\rangle / 4 h$

where $\left\langle v_{\mathrm{p}}\right\rangle$ is the average $\mathrm{P}$-wave velocity of the sedimentary layer above the reflector (Sheriff and Geldart 1982). Using Eq. 3, we computed depths $h$ to reflectors (Fig. 12) using average Pwave velocities from 2.0 to $2.75 \mathrm{~km} / \mathrm{s}$ as published for Cenozoic sediments (Hauser et al. 2001; Bala et al. 2005) and fundamental frequencies $f_{0}$ as observed in our dataset. The calculated $h$ match the known depths for the CCB (Fig. 12), 


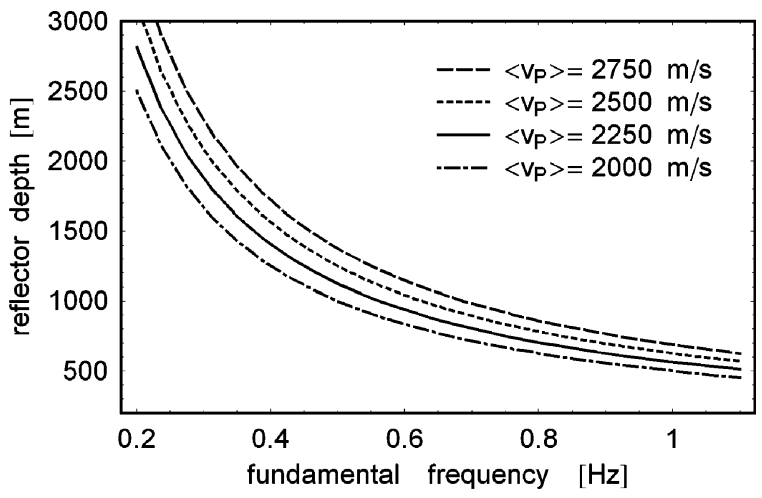

Fig. 12 Reflector depths as a function of the fundamental frequency $f_{0}$ for constructive interference from 0.2 to $1 \mathrm{~Hz}$ for P-wave velocities $\left\langle v_{\mathrm{p}}>\right.$ from 2.0 to $2.75 \mathrm{~km} / \mathrm{s}$

e.g. $h \sim 1,600-2,200 \mathrm{~m}$ for $f_{0} \sim 0.3 \mathrm{~Hz}$ and $h \sim$ $600-900 \mathrm{~m}$ for $f_{0} \sim 0.8 \mathrm{~Hz}$. Thus, positive interference is a very likely cause for the observed amplitude variations in Fig. 7. For a direct comparison of the calculated $h$, together with the observed $f_{0}$ $(0.43$ and $0.71 \mathrm{~Hz})$ and amplitude variations, these parameters are plotted together in Fig. 13. The depth of the reflector after Mândrescu et al. (2004) is displayed as isolines and grey shading; the area for positive interference with a specific $f_{0}$ is indicated in red. There is a coincidence of increased seismic amplitudes for regions where the depth of the $\mathrm{CCB}$ matches the resonance criterion given in Eq. 1. This correlation is found for the whole range of analysed teleseismic P-phases from 0.14 to $0.86 \mathrm{~Hz}$ (Fig. 7).

A similar frequency-dependent behaviour for PGA is indicated in Cioflan et al. (2004). They model wave propagation of Vrancea events across Bucharest, and their model S3 (2D profile) includes the dipping Quaternary and Mesozoic sedimentary layers. Their results reveal maximum amplitudes in NE Bucharest at $0.1-0.3 \mathrm{~Hz}$, in the city centre at $0.5-0.7 \mathrm{~Hz}$ and in SW Bucharest at $0.7-0.9 \mathrm{~Hz}$ for P-waves. Interestingly, the spatial frequency-dependent effect is less pronounced for radial $\mathrm{S}$-waves and negligible for transverse $\mathrm{S}$ waves (Cioflan et al. 2004).

The spatial P-wave amplitude variation at higher frequencies ( $>1 \mathrm{~Hz}$, Fig. 8) is less coherent than the low-frequency pattern (Fig. 7). Sometimes, significant amplitude changes occur between neighbouring station sites. At 1.43-8.75 $\mathrm{Hz}, \mathrm{P}$-wave amplitudes tend to decrease from the NW to SE (Fig. 8b-f). It is unlikely that this is due to a resonance effect as for the lower frequencies because the amplitude distribution is frequencyindependent at $1.43-8.75 \mathrm{~Hz}$. The median values at individual station sites are quite stable across this frequency range. Consequently, we interpret

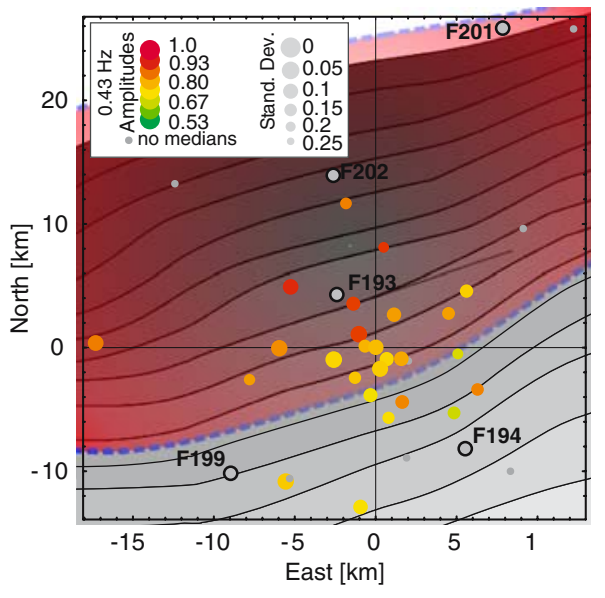

Fig. 13 Maps with median spectral P-wave amplitudes from the teleseismic waveforms at the URS network together with the depth of the Cenozoic-Cretaceous boundary $(C C B)$ as isolines and grey shading after Mândrescu et al. (2004). The regions of constructive interference due

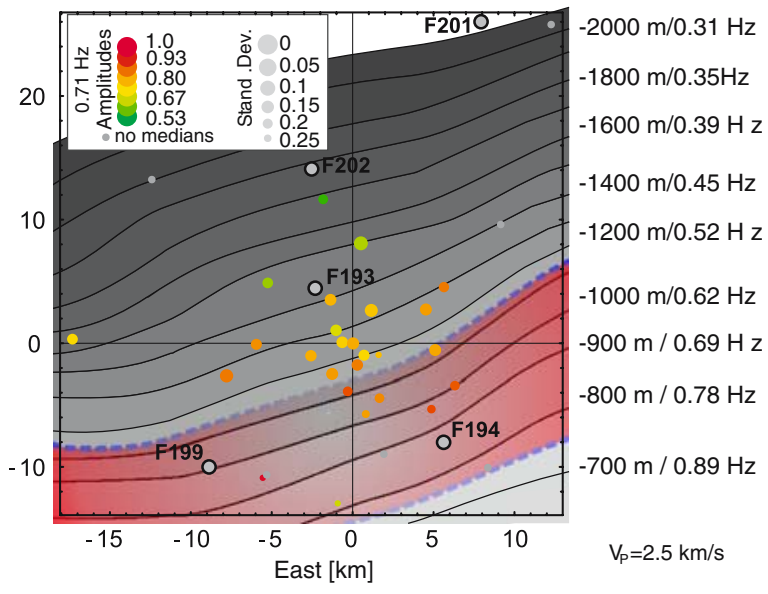

to the finite spectral resolution and estimated uncertainties of $\pm 0.1 \mathrm{~km} / \mathrm{s}$ in $\left\langle v_{\mathrm{p}}\right\rangle$ are shaded in red. The right scale indicates the depth to the CCB and corresponding frequencies for constructive amplitude interference with $\left\langle v_{\mathrm{p}}\right\rangle=$ $2.5 \mathrm{~km} / \mathrm{s}$. a dominant frequency $0.43 \mathrm{~Hz}$ and $\mathbf{b} 0.71 \mathrm{~Hz}$ 
this observation to be associated with local site effects that are mainly due to the near-surface geology close to the sites.

The S-wave amplitudes at $0.5-1 \mathrm{~Hz}$ are lower in the city centre compared to its urban surroundings (Fig. 10a, b). Within the city centre, the variation is small, which agrees with Wirth et al. (2003) who determined variation factors of $\sim 1.5$ for Fourier amplitude spectra of Vrancea strong motion records at $0.5-1 \mathrm{~Hz}$. The amplitude increase observed in the suburbs is quite large, but these values are also uncertain with standard deviations up to 0.6-0.75. Mândrescu et al. (2007) find increased amplitudes at $0.52-1 \mathrm{~Hz}$ for Vrancea S-waves which they explain as a result of resonance in the Quaternary sediments including the marls series (about upper 100-200 m). This resonance effect at $0.5 \mathrm{~Hz}$ in the north and $1 \mathrm{~Hz}$ in the south should only occur for strong shaking, e.g. $M>7$ for Vrancea earthquakes. This is well beyond the magnitude of the events during the URS experiment (Table 2). Aldea et al. (2004) show control periods $\left(T_{\mathrm{c}}\right)$ of response spectra across Bucharest for the 30 August 1986 Vrancea earthquake. Their result at $0.63-0.77 \mathrm{~Hz}$ indicates related strong motion in the southeastern part of the URS network partly consistent with our findings.

At $2-4 \mathrm{~Hz}$, the amplitude variation is relatively smooth (Fig. 10c-e). There are two to three stations with high relative amplitudes but also large standard deviations. The spatial pattern is quite stable for frequencies above $2 \mathrm{~Hz}$, and therefore, we propose that near-surface site effects dominate the amplitude behaviour. At 2-5 Hz, Wirth et al. (2003) find higher Fourier amplitudes towards the NW part of the city and lower values towards SE with a factor reaching 3-4. Such a trend is not supported by our dataset. Mândrescu et al. (2007) describe a seismic wave resonance at $1.42-3.3 \mathrm{~Hz}$ in the deposits above the marl complex (about upper $40-50 \mathrm{~m})$ during moderate $(5<M<7)$ Vrancea earthquakes. This also cannot be verified with our recordings of lower magnitude $(M \sim$ 4) Vrancea earthquakes and may indicate that the resonance properties of the Quaternary sediments behave nonlinearly depending on the input amplitude and possibly on the duration of shaking.

\section{Conclusions}

The recordings at the URS network in Bucharest allow us to study the amplification of seismic waves over a broad frequency range. For the first time, low frequent $(<1 \mathrm{~Hz})$ teleseismic Pwaveforms indicate a systematic NW-SE change in amplitude behaviour. This variation can be explained by the geological layering: There is a northward dipping Cenozoic sedimentary layer below the URS network which is underlain by more consolidated Mesozoic sedimentary rocks. Inside the Cenozoic sediments, constructive wave interference occurs that depends on the wavelength, and therefore frequency, as well as layer thickness and average seismic velocity. An average seismic velocity of about $2-2.5 \mathrm{~km} / \mathrm{s}$ in the sediments can well explain the observed amplification pattern at $0.14-0.71 \mathrm{~Hz}$ across Bucharest (Fig. 13). For the Bucharest area, the transition from systematic amplitude variations to typical site effects occurs at about $1 \mathrm{~Hz}$. Very local site effects are observed at high frequencies $(>1 \mathrm{~Hz})$ using $\mathrm{P}$ - and transverse $\mathrm{S}$-waveforms from Vrancea events. These site effects can vary at small distances, but seem to be mostly stable within a radius of some kilometres (Figs. 8 and 10). Within the metropolitan area of Bucharest, we find amplitude variations with a factor of $1-2$ for P-waves and 2-3 for transverse S-waves, which should be taken into account for seismic hazard assessment.

Acknowledgements URS was conducted as a joint Romanian-German experiment by the National Institute for Earth Physics Bucharest (Dr. S.F. Balan, Prof. G. Marmureanu) and the Universität Karlsruhe (TH) (Dr. K.-P. Bonjer, T. Diehl, Dr. J. Ritter, Prof. F. Wenzel). We thank all involved technicians and students that helped with the station installation and maintenance. Seismic waveform processing was done using SeismicHandler (Stammler 1993) and maps were produced with GMT (Wessel and Smith 1998). Funding for the field project was provided by the Deutsche Forschungsgemeinschaft through the Collaborative Research Centre 461 (CRC 461A1) 'Strong Earthquakes-A Challenge for Geosciences and Civil Engineering', the National Institute for Earth Physics, and the Universität Karlsruhe (TH). H. Sudhaus was funded by CRC 461, and this research is also conducted within the NATO Science for Peace Project SfP 981882 (Dr. Balan and Dr. Ritter). We thank Dr. K.-P. Bonjer and an anonymous reviewer for their useful comments. Moreover, we appreciate the proofreading of the manuscript by G. Tiernan and K. Leith. 


\section{References}

Aldea A, Lungu D, Arion C (2004) GIS mapping of seismic microzonation and site effects in Bucharest based on existing seismic and geophysical evidence. In: Lungu D, Wenzel F, Mouroux P, Tojo I (eds) Earthquake loss estimation and risk reduction 1, vol 1. Independent Film, Bucharest, pp 237-249

Atanasiu I (1959) Cutremurele de Pamint din Romania. Editura Academiei Republicii Populare Romine, Bucuresti, $195 \mathrm{pp}$

Bala A, Raileanu V, Mandrescu N, Zihan I, Dananau E (2005) Physical properties of the Quaternary sedimentary rocks in the eastern Bucharest area. Rom Rep Phys 57:151-163

Bartlakowski J, Wenzel F, Radulian M, Ritter JRR, Wirth W (2006) Urban shakemap methodology for Bucharest. Geophys Res Lett 33:L14310. doi:10.1029/ 2006GL026283

Cioflan CO, Apostol BF, Moldoveanu CL, Panza GF, Marmureanu Gh (2004) Deterministic approach for the seismic microzonation of Bucharest. Pure Appl Geophys 161:1149-1164. doi:10.1007/s000242496-8

Flatté SM, Wu RS (1988) Small-scale structure in the lithosphere and asthenosphere deduced from arrival time and amplitude fluctuations at NORSAR. J Geophys Res 93:6601-6614. doi:10.1029/JB093iB06p06601

Georgescu ES (2004) The partial collapse of Coltzea tower during the Vrancea earthquake of 14/26 October 1802: the historic warning of long-period ground motions site effect in Bucharest. In: Lungu D, Wenzel F, Mouroux P, Tojo I (eds) Earthquake loss estimation and risk reduction 2, vol 2. Independent Film, Bucharest, pp 331-340

Hauser F, Raileanu V, Fielitz W, Bala A, Prodehl C, Polonic $G$ et al (2001) VRANCEA99-the crustal structure beneath the southeastern Carpathians and the Moesian platform from a refraction seismic profile in Romania. Tectonophysics 340:233-256. doi:10.1016/S0040-1951(01)00195-0

Hauser F, Prodehl C, Landes M, VRANCEA working group (2002) Seismic experiments target earthquakeprone region in Romania. Eos Trans AGU 83:457463. doi:10.1029/2002EO000323

Hock S, Korn M, Ritter JRR, Rothert E (2004) Mapping random lithospheric heterogeneities from the Baltic Shield to the Massif Central, France. Geophys J Int 157:251-264. doi:10.1111/j.1365-246X.2004.02191.x

Lungu D, Scherer R, Zohar M, Coman O (1994) On the phenomenon of long predominant periods of ground vibration during the 1990, 1986, and 1977 earthquake records from Vrancea source. In: Savidis SA (ed) Earthquake resistant construction and design. AA Balkema, Rotterdam, pp 51-59

Lungu D, Aldea A, Cornea T (1999a) Dynamic characteristics of the existing building stock of Romania. In: Fryba L, Naprstek J (eds) Structural dynamics. AA Balkema, Rotterdam, pp 897-902
Lungu D, Cornea T, Nedelcu C (1999b) Hazard assessment and site-dependent response for Vrancea earthquakes. In: Wenzel F, Lungu D, Novak O (eds) Vrancea earthquakes: tectonics, hazard and risk mitigation. Kluwer, Dordrecht, pp 251-267

Lungu D, Demetriu S, Arion C (1999c) Seismic vulnerability of buildings exposed to Vrancea earthquakes in Romania. In: Wenzel F, Lungu D, Novak O (eds) Vrancea earthquakes: tectonics, hazard and risk mitigation. Kluwer, Dordrecht, pp 215-224

Mândrescu N, Radulian M (1999) Macroseismic field of the Romanian intermediate-depth earthquakes. In: Wenzel F, Lungu D, Novak O (eds) Vrancea earthquakes: tectonics, hazard and risk mitigation. Kluwer, Dordrecht, pp 163-174

Mândrescu N, Radulian M, Marmureanu Gh (2004) Site conditions and predominant period on seismic motion in the Bucharest urban area. Rev Roum Geophys 48:37-48

Mândrescu N, Radulian M, Marmureanu Gh (2007) Geological, geophysical and seismological criteria for local response evaluation in Bucharest urban area. Soil Dyn Earthqu Eng 27:367-393. doi:10.1016/ j.soildyn.2006.06.010

Moldoveanu CL, Radulian M, Marmureanu Gh, Panza GF (2004) Microzonation of Bucharest: state-of-theart. Pure Appl Geophys 161:1125-1147. doi:10.1007/ s00024-003-2499-5

Musson RMW (1999) Probabilistic seismic hazard maps for the North Balkan region. Ann Geofis 42:1109_ 1124

Oncescu MC, Marza VI, Rizescu M, Popa M (1999) The Romanian earthquake catalogue between 984-1997. In: Wenzel F, Lungu D, Novak O (eds) Vrancea earthquakes: tectonics, hazard and risk mitigation. Kluwer, Dordrecht, pp 43-47

Park J, Lindberg CR, Vernon FL III (1987) Multitaper spectral analysis of high-frequency seismograms. J Geophys Res 92:12675-12684. doi:10.1029/ JB092iB12p12675

Percival DB, Walden AT (1993) Spectral analysis for physical applications: multitaper and conventional univariate techniques. Cambridge University Press, New York

Radu C (1974) Contribution a l'etude de la seismicite de la Roumanie et comparaison avec la seismicite de sudest de la France. PhD thesis, Universite de Strasbourg, 404 pp

Raileanu V, Bala A, Hauser F, Prodehl C, Fielitz W (2005) Crustal properties from S-wave and gravity data along a seismic refraction profile in Romania. Tectonophysics 410:251-272. doi:10.1016/j.tecto.2004. 09.014

Ritter JRR, Balan SF, Bonjer K-P, Diehl T, Forbriger T, Marmureanu $\mathrm{G}$ et al (2005) Broadband urban seismology in the Bucharest metropolitan area. Seismol Res Lett 76:574-580

Sheriff RR, Geldart LP (1982) Exploration seismology 1-history, theory \& data acquisition. Cambridge University Press, Cambridge 
Slepian D (1978) Prolate spheriodal wave functions, Fourier analysis, and uncertainty-V: the discrete case. Bell Syst Tech J 57:1371-1429

Sokolov V, Bonjer K-P, Wenzel F (2004) Accounting for site effect in probabilistic assessment of seismic hazard for Romania and Bucharest: a case of deep seismicity in Vrancea zone. Soil Dyn Earthqu Eng 24:929-947. doi:10.1016/j.soildyn.2004.06.021

Stammler K (1993) SeismicHandler-programmable multichannel data handler for interactive and automatic processing of seismological analyses. Comput Geosci 19:135-140. doi:10.1016/0098-3004(93)90110-Q

Weber M (1994) Traveltime and amplitude anomalies at the seismic broadband array GRF. Geophys J Int 118:57-74. doi:10.1111/j.1365-246X.1994.tb04675.x
Wenzel F, Lungu D, Novak O (1999a) Vrancea earthquakes: tectonics, hazard and risk mitigation. Kluwer, Dordrecht

Wenzel F, Lorenz FP, Sperner B, Oncescu MC (1999b) Seismotectonics of the Romanian Vrancea area. In: Wenzel F, Lungu D, Novak O (eds) Vrancea earthquakes: tectonics, hazard and risk mitigation. Kluwer, Dordrecht, pp 15-25

Wessel P, Smith WHF (1998) New, improved version of generic mapping tools released. Eos Trans AGU 79:579. doi:10.1029/98EO00426

Wirth W, Wenzel F, Sokolov VY, Bonjer K-P (2003) A uniform approach to seismic site effect analysis in Bucharest, Romania. Soil Dyn Earthqu Eng 23:737758. doi:10.1016/S0267-7261(03)00073-3 